\title{
Exploring emerging learning needs: a UK-wide consultation on environmental sustainability learning objectives for medical education
}

\author{
Sarah C. Walpole1, Frances Mortimer ${ }^{2}$, Alice C. Inman², Isobel Braithwaite ${ }^{3}$, Trevor Thompson ${ }^{4}$
}

${ }^{1}$ Hull York Medical School, York, UK

${ }^{2}$ Centre for Sustainable Healthcare, Oxford, UK

${ }^{3}$ Medical School, University College London, UK

${ }^{4}$ Medical School, University of Bristol, UK

Correspondence: Sarah C. Walpole, Hull York Medical School, University of York, Heslington, York, UK

E-mail: sarah.walpole@hyms.ac.uk

Accepted: November 11, 2015

\begin{abstract}
Objectives: This study aimed to engage wide-ranging stakeholders and develop consensus learning objectives for undergraduate and postgraduate medical education.

Methods: A UK-wide consultation garnered opinions of healthcare students, healthcare educators and other key stakeholders about environmental sustainability in medical education. The policy Delphi approach informed this study. Draft learning objectives were revised iteratively during three rounds of consultation: online questionnaire or telephone interview, face-to-face seminar and email consultation.

Results: Twelve draft learning objectives were developed based on review of relevant literature. In round one, 64 participants' median ratings of the learning objectives were 3.5 for relevance and 3.0 for feasibility on a Likert scale of one to four. Revisions were proposed, e.g. to highlight

relevance to public health and professionalism. Thirty three participants attended round two. Conflicting opinions were explored. Added content areas included health benefits of sustainable behaviours. To enhance usability, restructuring provided three overarching learning objectives, each with subsidiary points. All participants from rounds one and two were contacted in round three, and no further edits were required.

Conclusions: This is the first attempt to define consensus learning objectives for medical students about environmental sustainability. Allowing a wide range of stakeholders to comment on multiple iterations of the document stimulated their engagement with the issues raised and ownership of the resulting learning objectives.

Keywords: Curriculum development, professionalism, education research, social determinants of health, environmental sustainability
\end{abstract}

\section{Introduction}

Environmental change is among the greatest challenges to health and healthcare of our time. Organisations including the World Health Organisation are emphasising the centrality of working towards environmental sustainability to protect public health. ${ }^{1}$ Environmental change significantly impacts the diseases that health professionals see and treat. Moreover, environmentally sustainable practices offer great opportunities to improve public health and healthcare services. Sustainable development -"development that meets the needs of the present without compromising the ability of future generations to meet their own needs" ${ }^{2}$ - offers many health'co-benefits'. ${ }^{3}$ Health services have a large ecological footprint. Reducing this footprint, saving money and improving patient care can go hand in hand. ${ }^{4}$

Medical education must prepare medical students to be professionals in, and leaders of, health systems. It must equip students with the knowledge, skills and attitudes to provide environmentally sustainable services. According to the World Medical Association, medical professionals should understand how environmental change affects the health of individuals, communities and societies. ${ }^{5}$ The translation of emerging health topics into medical curricula 
may begin 'bottom-up', with individual educators incorporating new material locally; or 'top-down', guided by evidence or recommendations from standard-setting or regulatory bodies. To date, introduction of teaching about environmental sustainability has generally been 'bottomup', without a conceptual framework or expert recommendations. ${ }^{6}$ Such 'bottom up' approaches range from action research projects with goals defined by learners (e.g. with nurses in $\mathrm{USA}^{7}$ and in $\mathrm{Brazil}^{8}$ ), to introduction of seminarbased, lecture-based or online teaching to address sustainability topics (e.g. through BMJ online ${ }^{9}$ ). While the bottom up approaches may bring smaller scale change, working 'top down' to impose new requirements may bring only superficial change; an ideal is to combine both approaches. ${ }^{10}$ Hence the need to develop learning objectives to bring authority and uniformity to guide curricular change from above, and to complement the engagement and learning achieved through 'bottom up' implementation of teaching to date.

This consultation was carried out at the request of the UK's General Medical Council (GMC) and aimed to identify learning and teaching needs related to the topic of environmental sustainability. Various methods have been used to develop guidelines about emerging topics in medical curricula; many draw on the policy Delphi method. ${ }^{11-14}$ Others have not done so explicitly, but have also sought to build consensus amongst stakeholders through consultation and iterative methodology. ${ }^{15,16}$ A modified Delphi explored learning objectives for a course about environment and sustainability, and, like this study, involved a wider pool of respondents $(n=188)$ in round one and a smaller group in round two to further explore ideas and develop recommendations. $^{17}$

The primary aim of this study was to address a lack of agreement on required learning about environmental sustainability, and create a consensus on learning objectives that should be included in undergraduate and postgraduate medical education (primarily in the UK, but potentially with transferability to other settings). Secondary aims were to engage a wide-range of stakeholders in medical education, and elucidate their views on the learning needs related to environmental sustainability of medical students and postgraduate doctors.

\section{Methods}

This consultation took the format of a policy Delphi, modified to involve a large number and range of stakeholders. The policy Delphi structures communication to allow a range of stakeholders to deal with a complex problem. The process seeks to build consensus by identifying divergent opinions, rather than make decisions on the basis of simple votes. ${ }^{18}$ The process is designed to guide policy analysis by structuring feedback from stakeholders who may have conflicting views, to ensure that all options and opinions are considered and the impact and acceptability of any decision is estimated.
The policy Delphi approach is appropriate for research in medical education because it recognises that actors with varying levels of knowledge and understanding of the topic area have valuable contributions to make, ${ }^{19}$ and the definition of 'expert' can extend to individuals who have experience of acting or advocating about the issue, have researched and informed themselves about the issue, and/or have an understanding of related or overarching concepts. Another benefit is that the policy Delphi method facilitates participants to learn more about the subject during the process of building consensus. ${ }^{20}$

Central to the policy Delphi are structured rounds of feedback, anonymity for participants, and opportunity to revise opinions based on interaction with other participants. Qualitative information is utilised by the committee to formulate the required policy, with inductive development of the consultation in response to feedback at each stage.

This policy Delphi is embedded in a constructivist paradigm, which falls within the interpretive paradigm. The constructivist paradigm is appropriate for this research question; one which cannot be answered through precise analysis of data and instead requires collection and integration of subjective judgments. ${ }^{21}$ In designing this study, we aimed to collect qualitative data to generate theories about the required learning in the sustainability domain. We aimed to assimilate and integrate the variety of subjective contributions through a process that allowed participants to develop their own understanding and contribute and agree to a consensus document. Whilst a challenge of using the Delphi approach is to ensure transparency and to recognise the influence of the committee who initially set the agenda, and in applying the findings from each round of consultation, a strength of the Delphi over other techniques such as brainstorming is that it provides all participants with a more equal voice rather than only the strongest opinions or loudest voices dominating the discussion. ${ }^{21}$

The committee for this consultation comprised four healthcare educators and two students, all with knowledge and teaching experience in the environmental sustainability domain. The first round enabled many stakeholders to comment on draft learning objectives drawn up by the committee. Round two involved an interactive seminar which allowed participants to understand, discuss and modify the learning objectives further. In round three, all participants were invited to comment on the revised learning outcomes and validate that their contributions were reflected.

Modification of the policy Delphi for this consultation involved draft competencies being developed by the authors with the aim of stimulating responses in round one, as it was felt that (in comparison with more open-ended questions) this would prompt participants to give more specific responses about the range of topics covered, the level of depth, and any particular areas they felt were strong or weak. Development of the initial draft learning objectives 
was informed by key papers on environmental sustainability and health ${ }^{22-24}$ and existing teaching on environmental sustainability in UK medical education ${ }^{25}$ (Appendix 1). Use of a background document allowed a wider number of participants (including those with limited prior engagement with environmental issues) to participate in the consultation, which was important because of the breadth of the topic area and range of disciplines and approaches with which it intersects. Including a wider range of participants in the development of the consensus is also important for this Delphi because there is no evident community or group of experts for this rapidly, but relatively newly, emerging area of medical education. The larger number of participants increases the possibility of incorporating a wider range of viewpoints.

In round one, an online questionnaire asked participants to rate the perceived importance and feasibility of implementing each learning objective; the coherence, relevance, format and feasibility of the whole document; and the importance and feasibility of individual proposed learning objectives, in each case on a four-point Likert scale. It also solicited suggestions for improvement. Invitations to participate were sent to 88 medical education and leadership institutions to cascade to others in their organisations. The heads of all 33 UK medical schools, all UK postgraduate deaneries and all medical Royal Colleges were invited to complete the questionnaire online or via telephone interview. The questionnaire remained open for 13 weeks. Thematic analysis of feedback identified suggestions for additions and alterations to content and structure, including comments that were reciprocal or refutational. Wherever possible, suggested alterations were incorporated.

In round two, a face-to-face seminar in London, the revised draft was shared with participants. All UK medical schools and the institutions contacted in round one were invited to send a representative member of staff. Members, including medical students, of the Sustainable Healthcare Education network were also invited to attend. Participants were all those who responded positively to this invitation. During this consultation, a World Café format ${ }^{26}$ was used in which delegates could spend time at three tables, which each had a different theme drawn from the contested issues in round one. These discussions helped to explore tensions which had arisen during round one. The facilitator at each table documented comments by taking notes during the discussion. Participants left anonymous written feedback at the end of the seminar. All comments and feedback were transcribed and organised into three pre-defined categories: (a) content of learning objectives, (b) structure and presentation of learning objectives, or (c) methods for implementation. Through discussion to reach consensus between the committee, all (a) and (b) responses were reviewed and where possible incorporated into a third draft of the learning objectives. Refutational responses were given particular consideration.

Round three aimed to ensure that participants' comments were interpreted correctly and had been incorporated as far as possible, and that participants could agree with the final learning objectives, whilst acknowledging that it is not possible to fully resolve all differences of opinion. The third draft learning objectives were circulated to all round one and two participants, with an invitation to comment. All comments were taken into account in a final refinement of the learning outcomes document.

All data were anonymised. All participants were informed of the study's nature and format on entry into the consultation, and could withdraw from the study at any time.

\section{Results}

\section{Participants, sample size and sampling methods}

There were 64 individual responses in round one (Table 1). Not every respondent stated which institution they are from, but the institutions that were represented included 25 universities, 6 postgraduate deaneries, 6 hospitals, one Royal College and four health agencies or NHS bodies. Some group responses were also received: two written submissions representing views collated in an organisation, and three reports of focus groups within different UK medical schools.

Table 1. Backgrounds of round one participants

\begin{tabular}{ll}
\hline Participants & $\mathrm{n}$ \\
\hline Medical Educators - undergraduate & 20 \\
Medical Educators - postgraduate & 15 \\
Students - medical & 12 \\
Trainee doctors & 5 \\
Health service managers & 2 \\
Educators - postgraduate, non-health & 1 \\
Sustainability experts & 1 \\
Students - allied health & 1 \\
Other - allied health & 7 \\
\hline
\end{tabular}

In round two, 33 invitees attended the seminar, including healthcare leaders from the UK's General Medical Council, Department of Health, Royal Colleges and NHS $(n=6)$; undergraduate medical educators from eleven medical schools $(n=13)$ and five postgraduate deaneries $(n=8)$; medical students from five medical schools $(n=6)$.

In round three, 88 participants were contacted and to reply if they opposed any of the learning objectives or wanted to suggest any further edits. Acknowledgement, endorsement and suggestions for edits were received from seven participants, but the suggestions for edits were seen by the committee to contradict findings from previous rounds or go beyond the scope of the document. When this was suggested to the respondents, they agreed that the edits should not be made. 


\section{Data collection and analysis, Round one}

In round one, median (and mean) ratings of the whole document were: coherence 4.0 (3.4), relevance 3.5 (3.3), formatting 3.0 (3.3) and feasibility 3.0 (2.7). In all areas, ratings ranged from one to four. Of the ten learning objectives, two had median feasibility rating of four, seven had median feasibility rating of three and one had median feasibility rating of 2 . Importance ratings were higher, with seven having a median importance rating of 4 .

Qualitative feedback from round one was overall positive, commenting that the learning objectives were both clear and applicable:

\footnotetext{
"It is logical, evidence based and mapped to the curriculum." Medical educator - postgraduate
}

"Clear narrative that moves through 'why' it is an issue, 'what' can be done and 'how' progress can be measured and achieved." Health service manager

Concerns and suggestions for improvement of the learning objectives emerged under four main themes: specific content, relevance and scope for application to medical curricula, feasibility of implementation, and format and presentation; Table 2 shows illustrative subsidiary themes.

Table 2. Themes emerging from analysis of qualitative data from phase one

\begin{tabular}{|c|c|}
\hline Heading - main theme & Subthemes (examples) \\
\hline $\begin{array}{l}\text { Specific content - } \\
\text { proposed additions }\end{array}$ & $\begin{array}{l}\text { - } \quad \text { Clear definition of sustainability } \\
\text { - } \quad \text { social and economic dimensions of } \\
\text { - } \quad \text { Population growth/ control } \\
\text { - Nutrition } \\
\text { - Sustainable/ ethical procurement } \\
\text { - Sustainable healthcare research } \\
\text { - Health service resilience } \\
\text { - Waste management } \\
\text { - Conflicting priorities, e.g. infection } \\
\text { control by introducing single use } \\
\text { equipment versus preserving and } \\
\text { reusing resources }\end{array}$ \\
\hline $\begin{array}{l}\text { Relevance and scope } \\
\text { for application to } \\
\text { medical curricula to } \\
\text { medical education }\end{array}$ & $\begin{array}{l}\text { - Relevance to health and healthcare } \\
\text { not always explicit } \\
\text { - Undergraduate versus postgradu- } \\
\text { ate } \\
\text { - } \quad \text { Core versus optional } \\
\text { - Stand-alone versus integrated }\end{array}$ \\
\hline $\begin{array}{l}\text { Feasibility of } \\
\text { implementation }\end{array}$ & $\begin{array}{l}\text { - Too many learning objectives, too } \\
\text { wide-ranging } \\
\text { - Too prescriptive (rather than en- } \\
\text { couraging critical thinking) } \\
\text { - Too much theory, need to be more } \\
\text { relevant to practice } \\
\text { - Need to link to existing curriculum } \\
\text { topics } \\
\text { - Need for training and CPD for } \\
\text { educators }\end{array}$ \\
\hline $\begin{array}{l}\text { Format and } \\
\text { presentation }\end{array}$ & $\begin{array}{l}\text { - Objectives and format should align } \\
\text { more closely with the GMC's 'To- } \\
\text { morrow's Doctors' } \\
\text { - Avoid jargon } \\
\text { - } \quad \begin{array}{l}\text { Need for multiple documents, some } \\
\text { simpler }\end{array}\end{array}$ \\
\hline
\end{tabular}

\section{Specific content}

Several participants advised that central concepts, such as sustainability, should be defined. Most comments supported the learning objective describing the relationship between environment and human health, e.g. "essential for all professionals including doctors" (Medical educator- Postgraduate) and "vital background, much needed" (Trainee doctor). In contrast, one participant stated that they felt this to be "more about being a good world citizen than a good doctor" (Medical educator - postgraduate) and another that it "should have been covered in school ... [and is] basic stuff for the first medical school term" (Medical Educator- Postgraduate).

One challenge was to balance the addition of important topics with the need for the final document to be concise, accessible and feasible to implement.

\section{Relevance and scope for application to medical curricula}

Participants recommended more clarity on the links between the learning objectives and the practice of medicine, and advice on where and how the learning objectives should be incorporated. The committee added clarification that the objectives were primarily intended for core undergraduate curricula, but may inform non-core modules and be relevant to postgraduates.

Responses also suggested that different types of curriculum must be considered, and that supporting materials need to cater for problem-based learning as well as traditional curricula. Respondents also discussed whether the outcomes were intended for integration within specialty teaching or included as stand-alone elements.

\section{Feasibility of implementation}

Participants highlighted space constraints in the medical curriculum and the challenge of teaching about environmental topics in enough detail to give students adequate sufficient understanding. A hierarchy of importance was suggested to assist educators in identifying key areas to incorporate.

"If there was going to be one hour of teaching what are the 1
or 2 key things you would like taught in that hour?" Vice
Dean - undergraduate medical education.

"The main thing is to emphasise that most can be integrated into existing teaching. The more examples of successful practice that are included the better." Undergraduate medical educator

\section{Format and presentation}

Practical suggestions were made about rewording and restructuring to make the draft learning objectives more accessible, user-friendly or effective.

The original twelve proposed learning objectives were condensed into three headline objectives with more detailed 
supporting material, in order to highlight priority concepts and issues while still addressing other important topics.

\section{Data collection and analysis, Round two}

Informed by the themes which arose during round one, the committee identified six areas to explore further: (1) helping educators and students to engage (2) teaching ethical aspects of environmental sustainability, (3) the impacts of long-term healthcare trends on sustainability and related teaching, (4) integrating sustainability across the curriculum, (5) implementation and teaching delivery, and (6) improving wording and structure (Appendix 2). Areas two and three relate to the content of the learning objectives.

On the subject of ethics, participants debated where environmental issues fall in relation to the duties of citizens and the duties of doctors. They discussed whether it is the role of medical education to address issues that every citizen should address, whether or not they are a health professional. Other topics of discussion were the relevance or otherwise of the Hippocratic Oath and the principle of nonmaleficence, whether knowing and supporting the laws and policies of healthcare institutions falls within the duty of a doctor, and the extent to which advocacy about environmental issues is a doctor's role. Participants also considered at what stage in training it is most useful to present ethical issues for trainees to explore.

On the topic of long term trends in healthcare, participants debated the extent to which doctors require an understanding about health systems and resource use. It was suggested that to enhance students understanding, they need to be able to define sustainability. It was further suggested that learning about sustainability may enhance students' understanding of public health and social determinants of health, and help them to see the relevance of these to their clinical practice.

Some feedback could not be incorporated due to contradictory responses. For example, regarding the original learning objective about resource use, comments were:

"This area would not be considered essential for a graduate to be competent $F 1$ doctor, perhaps something to develop as a postgraduate." (Educator- undergraduate medical)

"Very important to understand resources and the effect of these. I think quantifying the impact is much too in depth." (Student - medical)

Where advice was contradictory, decisions were made about which to follow based both on reference to the published literature and the expertise of the committee members. Some comments were felt to be beyond the scope of the learning outcomes, such as ethical procurement of medical equipment and respect for different cultures.

Responses related to implementation will inform future work. Key responses in this category included recognition that development of knowledge, skills and confidence of medical educators in this area is needed, and that supporting materials should be adapted to different curricula.

\section{Data collection and analysis, Round three}

In round three, seven responses were received. None suggested edits that were perceived to be in line with comments from previous rounds or upheld by the respondent when they were questioned about this, therefore no further edits were made to the learning objectives.

The final document contains three priority learning objectives aligned with the GMC's categories of doctor as scholar, doctor as practitioner and doctor as professional (Appendix 3). As a scholar, doctors require an understanding of how the environment and human health interact at different levels. As a practitioner, doctors must be able to apply knowledge and skills around sustainable healthcare in order to improve the environmental sustainability of health systems. As a professional, doctors must consider the ethical issues posed by the relationship between the environment and health, which was framed in terms of how the duty of a doctor to protect and promote health is shaped by the dependence of human health on the local and global environment.

\section{Discussion}

This three-stage consultation addresses the current lack of specific guidance ${ }^{6}$ on what learning related to sustainability and environmental issues undergraduate and postgraduate doctors should achieve and aims to provide a framework for curriculum development to address some of the problems encountered in developing learning objectives in a 'bottomup' manner, as has been done elsewhere for subjects such as quality improvement ${ }^{27}$ and communication skills. ${ }^{15}$

Participants almost unanimously supported the need for consensus learning objectives to inform teaching and curriculum development. The GMC outlines the duty of a doctor to protect and promote health, ${ }^{28}$ and participants recognised sustainability as fundamentally linked to this duty. Through the consultation, some topics were added (e.g. health co-benefits of sustainable behaviours) or expanded (e.g. ethical challenges associated with delivering environmentally-sustainable healthcare) from the initial draft document, while its structure was simplified to facilitate implementation. To address the many dimensions of sustainability, one learning objective addresses public health dimensions, another treats practical aspects in healthcare provision, and the third encourages exploration of ethical issues.

Consensus was reached amongst participants that the document should not dictate whether the objectives should be introduced as a stand-alone curricular topic or as a perspective through which to approach existing topics (such as health inequalities, ethics and leadership), leaving such decisions to individual medical schools. 


\section{Methods, strengths and limitations}

The consensus learning outcomes are consistent with curriculum recommendations from professional bodies ${ }^{29-}$ ${ }^{31}$ and peer-reviewed literature, ${ }^{32-34}$ suggesting that the results are transferable to medical curricula. Confirmability of the study is enhanced as rigorous reporting took place throughout the study period. Such reporting was regularly referred to at the time of write up, to reflect on the process and reflexivity.

The consultation was designed to enable dialogue and overcome the difficulty of eliciting meaningful input from stakeholders on a potentially unfamiliar topic. It is suggested that the Delphi technique is useful where ethical and social issues are paramount, rather than economic or technical problems. All of these are relevant to sustainability, and our study has primarily drawn out ethical and social tensions while recognising the need for further exploration of how economic and technical developments relate to the topic of sustainability and the learning needs of future doctors.

Anonymity of written responses in all three rounds allowed participants to give their views freely, ${ }^{19}$ which is a strength of this study. A disadvantage of anonymous responses that has been proposed is the lack of accountability and traceability means that responses may be given that would not be supported by the participant. ${ }^{36}$ Participants offered wide-ranging perspectives and expertise, which is important to ensure that different societal, health service and individual needs are considered. Untutored responses are useful in developing recommendations that are acceptable to a broad audience.

The design of this study allowed the inclusion of views from a relatively large number of participants, which increases the dependability of the results and their ability to represent the views of the larger population. ${ }^{37} \mathrm{We}$ acknowledge, however, that the sample size could have been larger to incorporate more views, especially of educators from around the UK. The process of exchanging views and allowing participants to modify their opinions and helped to address the complexity of this subject.

\section{Future research}

Validation of the acceptability, feasibility and usefulness, or otherwise, of the learning objectives will primarily be in the extent to which the learning objectives are implemented. As highlighted by participants, work is needed to give educators the skills and confidence to facilitate implementation.

The methods of this consultation can inform future work to set priorities in medical education. The method allows input from a range of stakeholders, and multiple revisions, which is particularly useful where there is not a small or well-defined stakeholder group, such as with the topic of environmental sustainability. In our increasingly interdependent and globalized world, complex systems and factors affect health and healthcare, and this approach lends itself to studying such complex topics.

Support for educators and curricular leads will aid implementation of these learning objectives. Future research may investigate students' baseline knowledge about environmental issues, effective pedagogies for learning and its impact on health professionals' practice.

\section{Conclusions}

This three-stage consultation has identified learning objectives on the topic of environmental sustainability for tomorrow's doctors. The learning objectives reflect the roles of a doctor as scholar, practitioner and professional.

The consultation advances our understanding of how environmental sustainability relates to medical education, by exploring the views of medical educators, students, healthcare professionals, and representatives of medical schools and other influential health organisations. It demonstrates methods for developing a consensus document in collaboration with a wide range of stakeholders. The outcome is a simple and adaptable educational framework that can inform both teaching and curriculum design.

\section{Acknowledgements}

We would like to thank Stefi Barna, the University of East Anglia and all participants. Funding was provided by the Higher Education Authority (grant) and Universities of Bristol and East Anglia (staff time and Cabot grant towards seminar costs).

\section{Conflict of Interest}

The authors declare that they have no conflict of interest.

\section{References}

1. World Health Organisation and Secretariat of the Convention on Biological Diversity. Connecting Global Priorities: Biodiversity and Human Health; Summary of the State of Knowledge Review. World Health Organisation; 2015 February 13 [cited 28 July 2015]; Available from: http://apps.who.int/iris/bitstream/10665/174012/1/9789241508537_eng.pdf. 2. Bruntland GH. Report of the World Commission on Environmental and Development: Our Common Future. United Nations; 1987 [cited 14 November 2012]; Available from: www.un-documents.net/our-commonfuture.pdf.

3. Ganten D, Haines A, Souhami R. Health co-benefits of policies to tackle climate change. The Lancet. 2010; 376(9755):1802-4.

4. Maughan D, Gibbs R. Facing the future: sustainability for the Medical Royal Colleges. Academy of Medical Royal Colleges, 2014 [cited 10 June 2015]; Available from: www.aomrc.org.uk/doc_download/9790-medicalroyal-colleges-sustainability-guide.html.

5. World Medical Association. Declaration of Delhi on Health and Climate Change, New Delhi. 2009 October 17 [cited 14 November 2012]; Available from: http://www.wma.net/en/30publications/10policies/c5/index.html.

6. Walpole SC, Pearson D, Barna S, Coad J. What do tomorrow's doctors need to learn about ecosystems? A BEME systematic review. Med Teach, 2015. [Unpublished paper]

7. Laustsen GR. Promoting ecological behavior in nurses through action research. Thesis. University of Colorado Health Sciences Center; 2005.

8. Takayanagui AMM. Trabalhadores de saúde e meio ambiente: açäo educa-tiva do enfermeiro na conscientizaçäo para gerenciamento de resíduos sólidos. Thesis. Universidade de Sao Paulo, 1993. 
9. BMJ online learning module, Climate change and health. [cited 27 October 2015]; Available from: http://learning.bmj.com/learning/moduleintro/cli-mate-change-health-science-impacts-.html?moduleId=10017515.

10. Fullan M. Coordinating top-down and bottom-up strategies for educational reform. In: Anson RJ, editor. Systemic reform: perspectives on personalizing education. Washington DC, US Department of Education: Office of Educational Research and Improvement; 1994.

11. de Villiers MR, de Villiers PJ, Kent AP. The Delphi technique in health sciences education research. Med Teach. 2005; 27(7):639-43.

12. Stewart J, O'Halloran C, Harrigan P, Spencer JA, Barton JR, Singleton SJ. Identifying appropriate tasks for the preregistration year: modified Delphi technique. BMJ. 1999; 319(7204):224-9.

13. Stirrat GM, Johnston C, Gillon R, Boyd K. Medical ethics and law for doctors of tomorrow: The 1998 Consensus Statement updated. J Med Ethics. 2010;36(1):55-60.

14. Kizawa Y, Tsuneto S, Tamba K, Takamiya Y, Morita T, Bito S, et al. Development of a nationwide consensus syllabus of palliative medicine for undergraduate medical education in Japan: a modified Delphi method. Palliat Med. 2012; 26(5):744-52

15. von Fragstein M, Silverman J, Cushing A, Quilligan S, Salisbury H, Wiskin C. UK consensus statement on the content of communication curricula in undergraduate medical education. Med Educ. 2008;42(11):1100-7.

16. Johnson O, Bailey S L, Willott C, Crocker-Buque T, Jessop V, Birch M, et al. Global health learning outcomes for medical students in the UK. The Lancet. 2012;379(9831):2033-5.

17. Wright TSA, Defields D. Determining the 'essentials' for an undergraduate sustainability degree program: a Delphi study at Dalhousie University. Journal of Education for Sustainable Development. 2012; 6(1):101-10.

18. Linstone HA, Turoff M. The Delphi method, Techniques and Applications. 2002 [cited 28 November 2012]; Available from: http://is.njit.edu/pubs/delphibook\#copyright.

19. Meskell P, Murphy K, Shaw DG, Casey D. Insights into the use and complexities of the Policy Delphi technique. Nurse Res. 2014; 21(3):32-9.

20. Rayens MK, Hahn EJ. Building consensus using the policy Delphi method. Policy Politics \& Nursing Practice. 2000; 1(4):308-15.

21. Hanafin SA. A review of literature on the Delphi technique, 2014 [cited 27 October 2015]; Available from: http://www.childrensdatabase.ie/ documents/publications/Delphi_Technique_A_Literature_Review.pdf. 22. Costello A, Abbas M, Allen A, Ball S, Bell S, Bellamy R, et al. Managing the health effects of climate change: Lancet and University College London Institute for Global Health Commission. Lancet. 2009; 373(9676):1693-733. 23. NHS Sustainable Development Unit. Saving Carbon, improving health: NHS Carbon reduction strategy for England. NHS SDU London 2009 [cited 15 January 2015]; Available from: http://www.sduhealth.org.uk/policy- strategy/engagement-resources/nhs-carbon-reduction-strategy-2009.aspx. 24. Mortimer F. The sustainable physician. Clinical Medicine. 2010; 10(2):110-1.

25. Braithwaite I, Mortimer F, Thompson T, Walpole SC, Barna S, Gillam S, et al. Case studies: UK medical school teaching on sustainability, climate and health, 2012[5 January 2015]; Available from: http://sustainabl ehealthcare.org.uk/sustainable-healthcare-education/resources/2013/05/ case-studies-teaching-climate-sustainable-healthc.

26. Brown J. Issacs D. The world café; shaping our futures through conversations that matter. San Francisco: Berrett-Koehler Publishers. 2005.

27. Ogrinc G, Headrick LA, Mutha S, Coleman MT, O’Donnell J, Miles PV. A Framework for teaching medical students and residents about practicebased learning and improvement, synthesized from a literature review. Academic Medicine. 2003; 78(7):748-56

28. GMC. Tomorrow's doctors, outcomes and standards for undergraduate medical education. London: General Medical Council; 2009.

29. AACN. Toward an environmentally sustainable academic enterprise: an AACN guide for Nursing Education, 2011 [cited 5 January 2015]; Available from: http://www.aacn.nche.edu/about-aacn/Sustainability.pdf.

30. Royal College Physicians. How doctors can close the gap: tackling the social determinants of health through culture change, advocacy and education. Policy statement. 2010 [cited 5 January 2015]; Available from: https://www.rcplondon.ac.uk/resources/how-doctors-can-close-gap.

31. WNA. Proposed WNA reference report \#1. Stat: Bulletin of the Wisconsin Nurses Association, 2008 [cited 5 January 2015]; Available from: http://search.ebscohost.com/login.aspx?direct=true\&db=jlh\&AN=20100804 83\&site=ehost-live

32. Bedsworth L. Preparing for climate change: a perspective from local public health officers in California. Environ Health Perspect. 2009; 117(4):617-23.

33. Watts N, Adger WN, Agnolucci P, Blackstock J, Byass P, et al. Health and climate change: policy responses to protect public health [cited 5 January 2015]; Available from: http://dx.doi.org/10.1016/S01406736(15)60854-6.

34. Viero CM, et al. Percepção de docentes enfermeiros sobre a problemática ambiental: subsídios para a formação profissional em enfermagem. Texto \&amp; contexto enferm. 2012;21(4):757-765.

35. Gupta UG, Clarke RE. Theory and applications of the Delphi technique: a bibliography (1975-1994). Technological Forecasting and Social Change. 1996; 53(2):185-211

36. Keeney S, Hasson F, McKenna HP. A critical review of the Delphi technique as a research methodology for nursing. Int J Nurs Stud. 2001; 38(2):195-200.

37. Hasson F, Keeney S. Enhancing rigour in the Delphi technique research. Technological Forecasting and Social Change. 2011; 78(9):1695-704. 


\section{Appendix 1}

Key resources that informed the development of initial draft learning outcomes

Case studies from the Sustainable Healthcare Education network, Centre for Sustainable Healthcare were accessed in September 2011 from:

- http://sustainablehealthcare.org.uk/sustainable-healthcare-education and used to inform the initial learning outcomes document.

The following papers were used to inform the consultation draft document

- $\quad$ Bodenheimer T, Lorig K, Homan H. Patient Self-management of Chronic Disease in Primary Care. JAMA: The Journal of the American Medical Association. 2002;288(19):2469-75.

- Climate Change Act 2008. [cited 2012 Apr 19]; Available from: http://www.legislation.gov.uk/ukpga/2008/27/part/1.

- Connor A, Lillywhite R, Cooke MW. The carbon footprint of a renal service in the United Kingdom. QJM. 2010;103(12):965-75.

- Costello A, Abbas M, Allen A, Ball S, Bell S, Bellamy R, et al. Managing the health effects of climate change: Lancet and University College London Institute for Global Health Commission. Lancet. 2009;373(9676):1693-733.

- Ecosystems and Human Well-Being: Health Synthesis from the Millennium Ecosystem Assessment. World Health Organisation; 2005. Available from: http://www.who.int/globalchange/ecosystems/ecosys.pdf.

- $\quad$ Kim CS, Spahlinger DA, Kin JM, Billi JE. Lean health care: What can hospitals learn from a world-class automaker? Journal of Hospital Medicine. 2006;1(3):191-9.

- $\quad$ Maller C, Townsend M, Pryor A, Brown P, St Leger L. Healthy nature healthy people: "contact with nature" as an upstream health promotion intervention for populations. Health Promot Int. 2006;21(1):45-54.

- $\quad$ NHS England Carbon Footprint (published 2012). NHS Sustainable Development Unit; 2012. Available from: http://www.sdu.nhs.uk/documents/publications/NHS_Carbon_Footprint_Published_2012.pdf.

- $\quad$ Raffle AE. Oil, health, and health care. BMJ. 2010;341:c4596.

- Rockström J, Klum M. The Human Quest: Prospering Within Planetary Boundaries. Princeton University Press; 2012. Available from: http://www.ecologyandsociety.org/vol14/iss2/art32/main.html.

- Royal Society. Climate change: a summary of the science [Internet]. The Royal Society; 2010. Available from: http://royalsociety.org/climate-change-summary-of-science/.

- $\quad$ Schroeder K, Thompson T, Frith K, Pencheon D. Sustainable Healthcare. Wiley-Blackwell; 2012. 


\section{Appendix 2}

Feedback from round two

1. Helping educators and students to engage

a. Make relevant to patient care - how will this affect the patient in front of me, clinical cases

b. Highlight evidence of benefits to patients/public

c. Need local champions

d. Engage students

e. Have sustainability as a theme on national conferences

f. Use peer teaching

g. Seek funding

2. Teaching ethical aspects of environmental sustainability,

a. Embed in duties of a doc, Embedding it in the other duties of health professionals: care of patients today and tomorrow (new strapline of NHS England 'future generations') - ethics, externalities, doing more good than harm.

b. Long term view

c. SOLUTION focused and POSITIVE, not PROBLEMS focussed and NEGATIVE

d. Good to hear that it is not all about CLIMATE CHANGE

e. $\quad$ Dr as a citizen domain (in GMCTD)

3. The impacts of long-term healthcare trends on sustainability and related teaching,

a. Focus on preventive care

b. Patient autonomy

c. Link with public health

d. Integrate with community care

e. Integrate with social determinants of health

f. Integrate with communication

g. Define sustainability; meeting the needs of today without prejudicing the needs of tomorrow (who currently have no choice and voice)

h. Sustainability needs to be defined. i.e. the biggest wins come from improving lifestyle and public health and that too much of a focus on carbon/ waste reduction side-line this issue

4. Integrating sustainability across the curriculum,

a. Need for culture change - society and in healthcare

b. Support the normative goals with interest of individuals and positivity and hedonic goals

c. Link with an MDT approach

d. Make it patient centred - listen to patients. There is a patient and public mandate

5. Implementation and teaching delivery

a. Integration across curriculum; a cross cutting theme

b. Also need blocks of teaching on this to avoid it being side lined

c. Taught by physicians / surgeons so that students can recognise that sustainability is vital for good medical practice in all specialities.

d. Provide supporting materials and train trainers

e. 'Train the trainers' programme: rather than doing this centrally, why not suggest it as an initiative and see what range of practices arise?

f. Multi-stakeholder engagement and involvement - GMC, Royal Colleges, Deans etc., Getting GMC, Royal Colleges to endorse the PLO's

Assessment

Important/only way to get this recognised

Way of measuring impact of teaching this - will it affect practice? - How will it be measured?

Portfolio better means of assessing than OSCES / one off assessments, because allows assessment to be reflective/continual 


\section{Appendix 3}

Learning outcomes on completion of the study Introduction

The global community faces major environmental challenges that impact on the health of current and future generations, especially in those areas that are most economically and geographically vulnerable. We can safeguard health by using sustainable approaches that reduce the environmental impact of our actions. Medical education is central to a sustainable future for healthcare and in September 2011 the General Medical Council asked the Sustainable Healthcare Education (SHE) Network to make recommendations on the priority learning outcomes for sustainability, to inform the on-going development of undergraduate and postgraduate medical curricula.

Although sustainability requires some new curricular material, it is primarily a perspective through which to approach existing topics, such as health inequalities and medical leadership. The learning outcomes have been designed to promote critical thinking, and development of the skills necessary to respond to change and uncertainty.

\section{Priority learning outcomes}

a. Describe how the environment and human health interact at different levels.

b. Demonstrate the knowledge and skills needed to improve the environmental sustainability of health systems.

c. Discuss how the duty of a doctor to protect and promote health is shaped by the dependence of human health on the local and global environment.

Expanded learning outcomes

This section provides suggestions for more detailed knowledge and skills relevant to each of the priority learning outcomes:

1. Describe how the environment and human health interact at different levels

Doctor as scholar and scientist

a. Outline the dependence of human health on global and local ecological systems, which supply essentials such as air, water and a stable climate.

b. Discuss the contribution of human activity and population size to global environmental changes such as climate change, biodiversity loss and resource depletion.

c. Describe the mechanisms by which human health is affected by environmental change, for example through changes in disease vectors, exposure to extreme weather, migration and reduced food security.

d. Describe features of a health-promoting local environment, in community and healthcare settings, to include access to green spaces, clean air and an active travel infrastructure.

2. Demonstrate the knowledge and skills needed to improve the environmental sustainability of health systems

Doctor as practitioner

a. Define the concept of environmental sustainability.

b. Explain how trends in demographics, technology, and climate and resource availability may affect our ability to provide healthcare into the future.

c. Describe, with examples, the different types of environmental impact resulting from healthcare provision, and how these may be measured.

d. Identify ways to improve the environmental sustainability of health systems - in individual practice, in health service management, and in the design of care systems.

e. Identify potential synergies between policies and practices that promote environmental sustainability and those that promote health.

3. Discuss how the duty of a doctor to protect and promote health is shaped by the dependence of human health on the local and global environment.

Doctor as professional

a. Explain how the health impacts of environmental change are distributed unequally within and between populations and the disparity between those most responsible and those most affected by change.

b. Recognise and articulate personal values concerning environmental sustainability, given the relationship between the environment and the health of current and future generations.

c. Discuss ethical tensions between allocating resources to individual patients and protecting the environment upon which the health of the wider community depends.

d. Demonstrate awareness of organisational sustainability policies and the legal frameworks for reducing carbon emissions. 